\title{
كلمة العـدد
}

يصدر العدد الساد و السبعون من المجلة المصرية لبحوث الإعلام منضمنأ

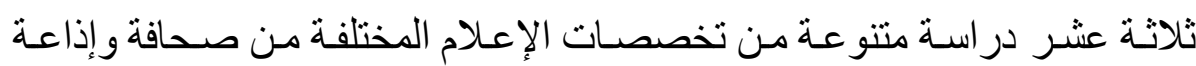

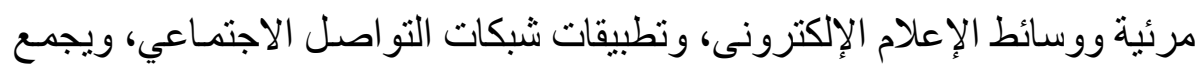

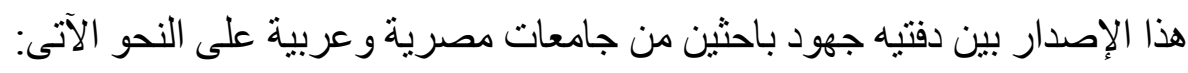

\section{بحوث علمية مهكمة:}

\section{أولاً: بحوث الصحافة الالكترونية والرقمية}

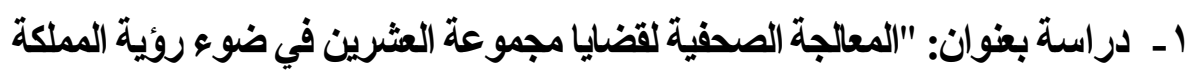

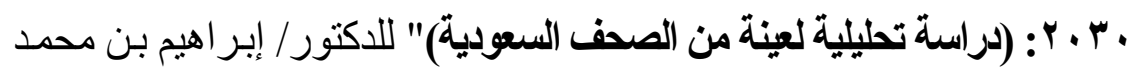

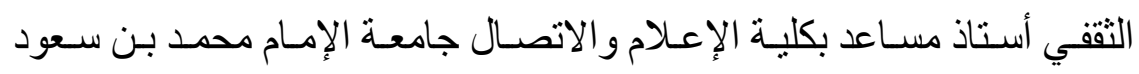

$$
\text { الإسلامية }
$$

r- دراسة بعنوان: "التماس الجمهور السـودي أم للمعلومـات من رجال الدين الإين

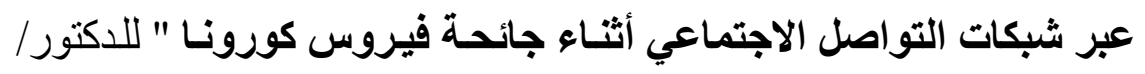

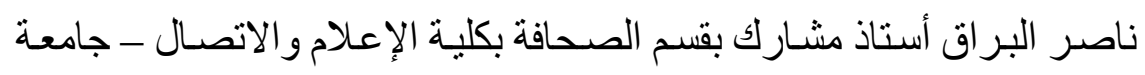

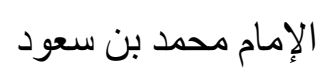

r- دراسة بغنوان: "دور الصفحات الرسمية للمؤسسات الحكومية علي شبكات

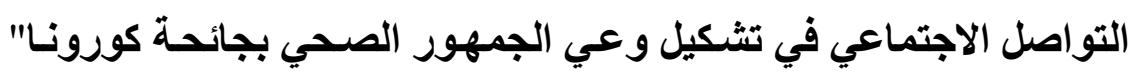

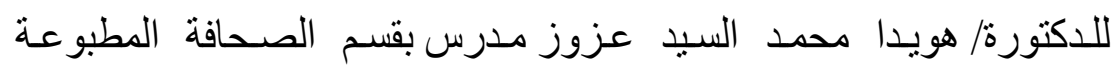

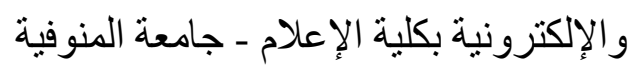

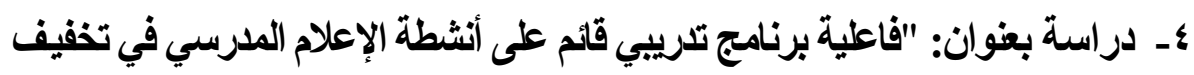

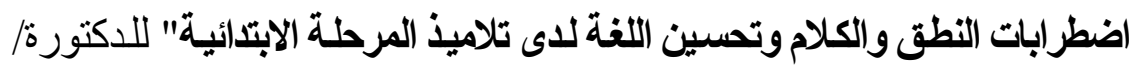

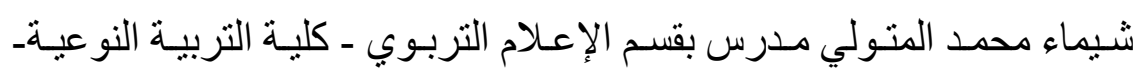

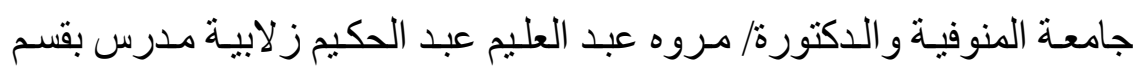
الاعلام التربوي ـ كلية التربية النوعية- جامعة المنوفية. 
هـ ـ دراسة بعنوان: "اعتماد مستخدمي شبكات التواصل الاجتماعي في السعودية على الإعل

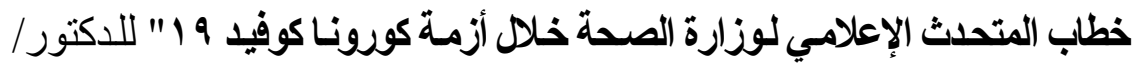

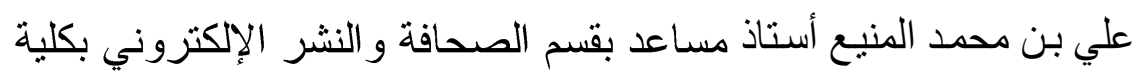

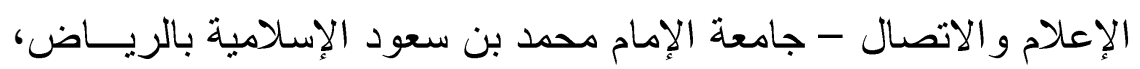
و الدكتور / فيصل بن محمد العقيل أستاذ مسـاعد بقسم الإعلام بكلية الآداب جامعة الملك سعود بالرياض.

\section{ثانياً: بحوث الإذاعة والتليفزيون والإعلام الرقمى بالري}

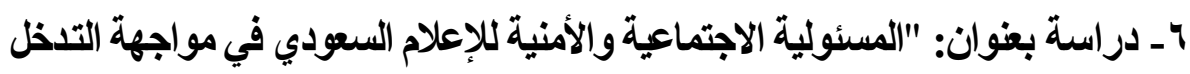

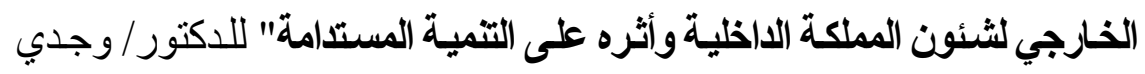

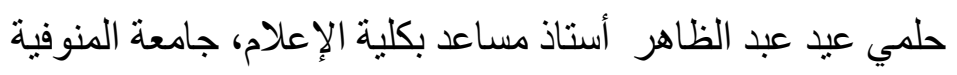
ثالثاً: بحوث الاتصالات التسويقية المتكاملة وبحوث الر أي العام:

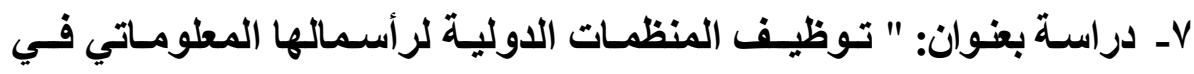

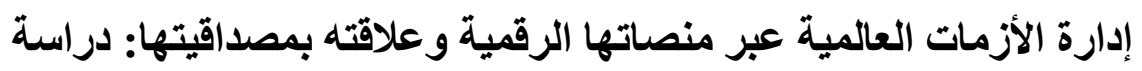

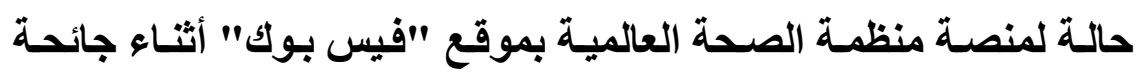
كورونا" للاكتور / إسلام أحمد عثمان أستاذ مساعد بقسم العلاقات العامة بكلية

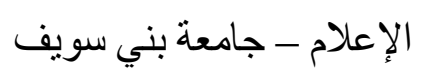

^- دراسة بعنوان: "توظيف وسـائل التواصل الاجتمـاعي في ممارسـة الأدوار

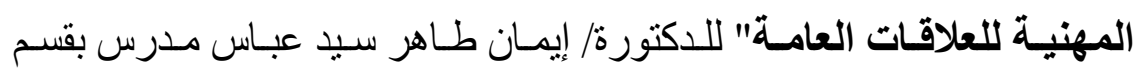
العلاقات العامة و الإعلان بكلية الإعلام - جامعة القاهرة

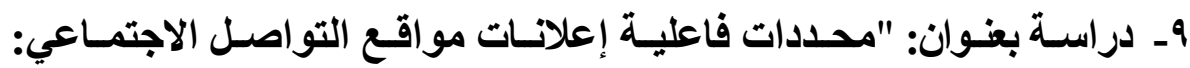

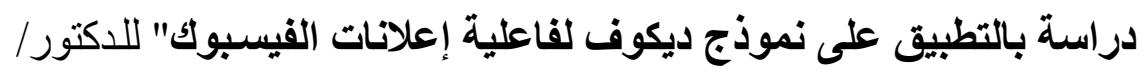
أحمد عبد السلام مدرس بقسم العلاقات العامة و الإعلان، كلية الإعلام، جامعة لدانة

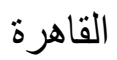

• 1ـ دراسة بغنوان: "واقع ممارسة أنشطة الإعلام التربوى بالمكتبات العامـة

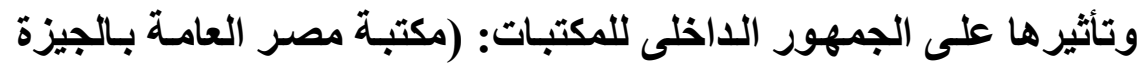


نموذجاً)" للاكتورة/ ريهام أحمد محمد زكى مدرس الإذاعة و التليفزيون بقسم الإعلام التربوى بكلية التربية النو عية - جامعة القاهرة.

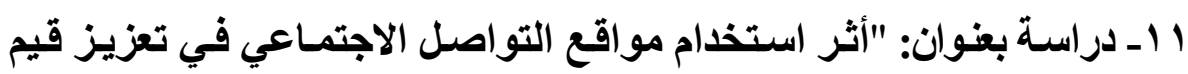

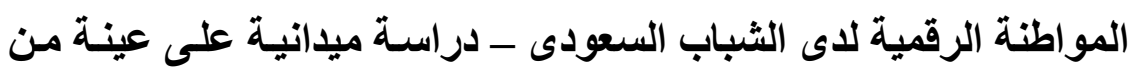

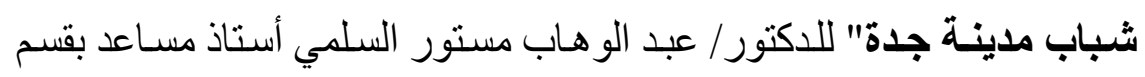

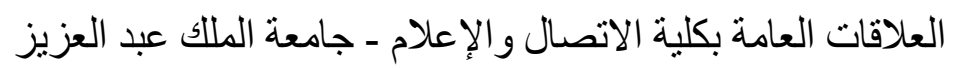
ب ا ـ دراسة بغوان: "اتجاهات طالبات الجامعات البحرينية نحو التسامح الداينى

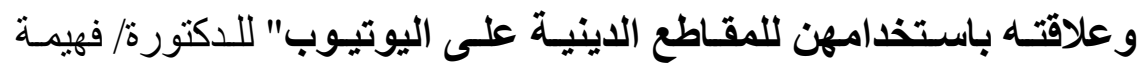
عبدالله محمد أستاذ مساعد بالجامعة الأهلية بمملكة البحرين. رابعاً: بحوث علمية من منطلبات الحصول على درجة الدكتوراه:

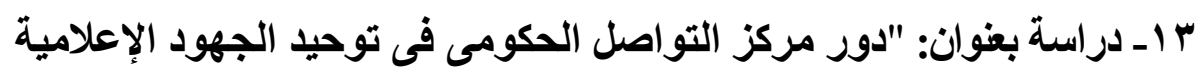

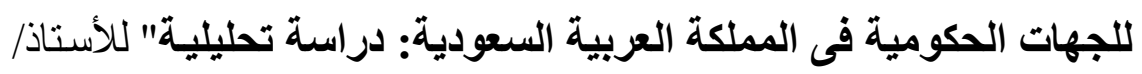

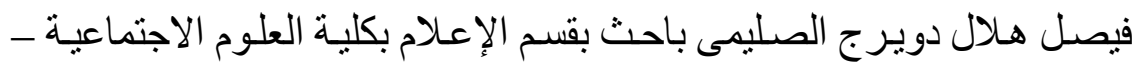
جامعة أم القرى بالمملكة العربية السعودية.

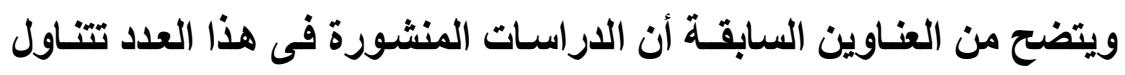

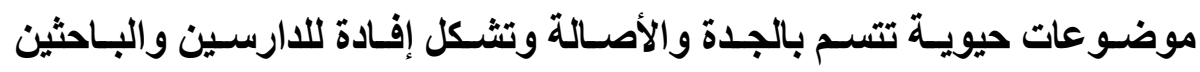

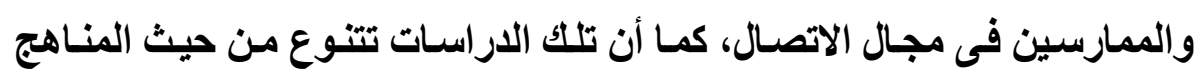
وطرق البحث المستخدمة مثلما تتنوع من حيث الموضول عات والأفكار والخلفيات

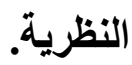

$$
\text { والله ولى التوفيق }
$$

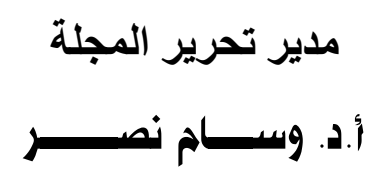

وكيل الكلية لنشئون الدراسات العليا و البحوث 